\title{
Programmable Living Materials Constructed with Dynamic Covalent Interface between Synthetic Polymers and B. subtilis
}

\author{
Hyuna $\mathrm{Jo}^{1}$ and Seunghyun $\operatorname{Sim}^{1,2,3 *}$ \\ ${ }^{1}$ Department of Chemistry, University of California Irvine, Irvine, California 92697, United \\ States \\ ${ }^{2}$ Department of Chemical and Biomolecular Engineering, University of California Irvine, Irvine, \\ California 92697, United States \\ ${ }^{3}$ Department of Biomedical Engineering, University of California Irvine, Irvine, California \\ 92697, United States
}

\begin{abstract}
With advances in the field of synthetic biology increasingly allowing us to engineer living cells to perform intricate tasks, incorporating these engineered cells into the design of synthetic polymeric materials will enable programming materials with a wide range of biological functionalities. However, employable strategies for the design of synthetic polymers that seamlessly integrate cellular functionalities in materials are still largely limited. Herein, we report the first example of programmable living materials constructed with a dynamic covalent interface between designed synthetic polymers and engineered $B$. subtilis cells. We identified a molecular
\end{abstract}


motif that forms reversible dynamic covalent bonds on B. subtilis cell surface. Combining block copolymers bearing this motif with genetically engineered $B$. subtilis yields programmable living materials that can be equipped with functionalities such as biosensing and on-demand elution of recombinant proteins. We further demonstrated that encapsulated cells could be reversibly retrieved and subjected to biological analyses. This work advances the current capabilities in engineered living materials, establishes the groundwork for building a myriad of synthetic polymeric materials integrating engineered living cells, and provides a platform for understanding the biology of cells confined within materials.

\section{INTRODUCTION}

Natural biological materials - such as wood, bone, and skin - comprise living cells and macromolecular scaffolds. The seamless integration of living cells into a structural scaffold in these natural materials enables complex biological tasks that are not possible with purely synthetic materials or cells alone. We see this in bone as it provides structural support, serves as a mineral reservoir, and produces red blood cells, all at the same time. ${ }^{1}$ The capacity of these biological materials to coordinate such complex tasks naturally motivates engineering of their synthetic counterparts. With advances in the field of synthetic biology increasingly allowing us to engineer living cells to perform intricate tasks, incorporating engineered living cells into the design of polymeric materials will enable high-performance polymeric materials equipped with a wide range of biological functionalities. In particular, Bacillus subtilis offers unique advantages as a building block for engineered living materials: It is genetically tractable, exhibits extraordinary secretion capacity, lacks toxic byproducts, and survives harsh environments by forming dormant spores. ${ }^{2}$ Motivated by these characteristics, recent studies have exploited biologically-derived 
macromolecules for producing living materials with $B$. subtilis. While González and colleagues used agarose hydrogels containing engineered B. subtilis spores for 3-dimensional printing, ${ }^{3}$ Huang and co-workers showcased printable living materials based on B. subtilis biofilms, which can be manipulated by bacterial amyloid Tas A production. ${ }^{4}$ Recently, Kang and colleagues engineered $B$. subtilis to produce self-assembling proteins and demonstrated in situ silica biomineralization. ${ }^{5}$

These living materials are essentially composite materials comprising at least two different physical and chemical components: macromolecules and living cells. Their mechanical and dynamic properties therefore should strongly depend on the molecular composition of the interface. However, bottom-up strategies for designing synthetic polymers that form a well-defined interface with living cells in order to seamlessly integrate living functionalities in materials are still largely limited. Our understanding of the biology of cells confined in materials is also limited because of the inherent physical barrier to detailed biological analysis and the lack of a platform allowing on-demand release of cells. In order to address these technological gaps, the ideal interface between polymeric materials and living cells should be molecularly well-defined, provide sufficient connection and collective bond strength for seamless integration, and provide means to capture and release encased cells reversibly. Dynamic covalent chemistries have attracted significant attention as a strategy for developing non-living polymeric materials that are adaptable, stimuli-responsive, and self-healing. ${ }^{6-13}$ Among these dynamic covalent systems, boronic acids form dynamic covalent bonds with 1,2- or 1,3-diol species and undergo rapid exchange when competing diols are present at ambient conditions in aqueous media. ${ }^{8-12} \mathrm{We}$, therefore, expected that utilizing boronic ester-mediated covalent bond formation for building the cell-material interface would yield adaptive and dynamic living materials. 
Here, we report programmable living materials constructed with a dynamic covalent interface between synthetic polymers and engineered B. subtilis cells (Fig. 1). We demonstrated that 3acetamidophenylboronic acid (APBA) and polymers containing APBA repeating units form dynamic covalent bonds with diols on the B. subtilis cell surface. In addition, we observed a multivalent effect in polymer binding to $B$. subtilis with complete reversibility when competitive diol species are present. Telechelic block copolymers, designed and synthesized based on these findings, crosslink B. subtilis cells and yield stable self-standing living materials in a hydrogel form. Harnessing engineered B. subtilis with genetically-encoded functionalities, we demonstrate that these living materials can be useful for biosensing and eluting recombinant proteins. We further show that the dynamic covalent interface enables encapsulated cells to be retrieved ondemand upon immersing these materials in solutions containing competitive diols, a critical feature that enables further biological analysis.

\section{RESULTS AND DISCUSSION}

\section{3-Acetamidophenylboronic acid (APBA) binds to B. subtilis cell surface.}

We first identified a chemical motif that binds to B. subtilis cell surface. $B$. subtilis is a grampositive organism with a peptidoglycan cell wall. The cell surface of $B$. subtilis comprises a disordered mesh of crosslinked peptidoglycan and teichoic acids..$^{14}$ Teichoic acids are anionic polymers with glycerol phosphate or ribitol phosphate backbone. ${ }^{15}$ There are two different types of teichoic acids; wall teichoic acid and lipid teichoic acid. Wall teichoic acids are covalently linked to the $\mathrm{N}$-acetylmuramic acid residues of peptidoglycan, and lipid teichoic acids have a lipid anchor which is embedded in the outer leaflet of the cell membrane. The hydroxyl groups in the main chain of teichoic acids are modified with D-alanine or glucose. We hypothesized that APBA 
would form dynamic covalent bonds with available 1,2-cis diols on B. subtilis, including glucose side chains in surface teichoic acids (Fig. 2a), and set out to test this hypothesis. A fluorescent probe with the APBA motif, APBA-sCy5, was synthesized by a reaction of sulfo-cyanine 5 (sCy5) NHS esters and 3-aminophenylboronic acid in the presence of triethylamine for $16 \mathrm{~h}$ (Fig. 2b, Supplementary Fig. 1). We also prepared a control probe molecule carrying a trisaminomethane (Tris) group instead of the APBA unit, Tris-sCy5 (Fig. 2b, Supplementary Fig. 2). A strong fluorescence emission on the B. subtilis (PY79 laboratory strain, abbreviated as WT) cell surface was observed when they were treated with APBA-sCy5 (Fig. 2c) whereas cells treated with TrissCy5 did not show appreciable fluorescence in the same setting (Fig. 2d). Fluorescence spectroscopy $\left(\lambda_{\mathrm{ex}}=630 \mathrm{~nm}\right)$ of these solutions corroborated the specific binding activity of APBA, with cell suspensions treated with APBA-sCy5 being 9-fold more emissive than those treated with Tris-sCy5 (Fig. 2i).

In an effort to molecularly understand the binding behavior of APBA-sCy5 on the cell surface of $B$. subtilis, we utilized a $\operatorname{tag} E$-deletion mutant. The $\operatorname{tag} E$ gene encodes a glycosyltransferase that is responsible for wall teichoic acid glycosylation, and deletion of this gene results in the loss of glucose side chains in the poly(glycerol phosphate) backbone. ${ }^{16}$ When B. subtilis tagE-deletion mutant $(\Delta \operatorname{tagE})$ was treated with APBA-sCy5, fluorescence localization on the cell surface was similar to that of WT B. subtilis cells but was of lower intensity on the cell surface (Fig. 2e). The bulk fluorescence measurement of the cell suspension corresponded with this observation, with $\Delta$ tagE resulting in 57\% lower total fluorescence than that of the WT B. subtilis (Fig. 2i). This result suggests that glucose side chains on wall teichoic acid serve as one of the major binding sites for APBA. We speculate that terminal diols at the chain end of teichoic acid are another likely binding site of APBA. The molecular composition of the cell surface of gram-negative bacteria such as $E$. 
coli is distinct from gram-positive bacteria, as they have outer phospholipid membranes decorated with membrane proteins and lipopolysaccharide. Corroborating our hypothesis, a PBS suspension of $E$. coli (laboratory strain) treated with APBA-sCy5 did not show appreciable surface labeling (Figs. 2g and 2i and Supplementary Fig. 18).

Polymers with APBA repeating units bind to $B$. subtilis cell surface and exhibit a multivalent effect.

We demonstrated that APBA-containing polymers exhibit a multivalent effect in binding to $B$. subtilis cell surface. APBA-containing, fluorescent polymers were synthesized through reversible addition-fragmentation chain-transfer (RAFT) polymerization (Fig. 3a) to understand the nature of the interaction between $B$. subtilis cell surface with macromolecules containing APBA motif. The terminal chain transfer groups on the polymers were cleaved by butylamine for subsequent conjugation of maleimide-sCy5 with the thiol groups at the chain termini. ${ }^{17}$ Gel permeation chromatography (GPC, Fig. 3b) of the reaction mixture showed polymers having molecular weights of 7,176 g/mol (P1), 8,872 g/mol (P2), and 11,103 g/mol (P3), which was in reasonable agreement with the ${ }^{1} \mathrm{H}$ NMR results (Supplementary Figs. 3-8).

Fluorescence microscopy revealed that the localization patterns of the polymers on the cell surface are strikingly different from that of monomeric APBA (Figs. 3e-j). While the monomeric form binds uniformly on the cell surface, fluorescent puncta were detected from the bound P1 and P2 to the cells (Figs. 3h and 3i), presumably due to the entangled polymer chains in local areas of the cell surface. Corroborating this result, hydrodynamic sizes detected from dynamic light scattering analysis indicated that APBA-containing polymers exist in aggregated forms in aqueous solutions (Fig. 3c). Interestingly, mixtures of the P3 and B. subtilis cells yielded various sizes of cellular aggregates that colocalize with strong fluorescence from the fluorescently labeled polymer 
(Figs. $3 g$ and 3j). This result suggests that a long chain of P3 serves as an intracellular crosslinking agent by providing binding sites for more than one cell (Fig. 3d). The numbers of bound polymers to the cells were evaluated based on bulk fluorescence measurements of the labeled, washed, and resuspended cell suspensions (Fig. 3k and Supplementary Figs. 24-27). The intensity values are normalized by the colony-forming unit $(\mathrm{CFU})$ of the cell suspension used for each sample prior to the polymer treatment. The estimated average number of polymer molecules per one $B$. subtilis cell increases with the number of APBA repeating units in these polymers. We speculate that the aggregation behaviors of these polymers may explain the observed multivalent effect in binding affinity to the cell. In addition, since one of the primary binding sites of the APBA to B. subtilis cell surface is the glucose side chains in wall teichoic acid, the multivalent effect in polymer binding to the B. subtilis surface may be due to the bi-dentate bridge of two adjacent APBA units binding to one glucose molecule in the furanose form via 1,2- and 5,6-cis-diols. ${ }^{18-20}$

The estimated average number of the monomeric form of APBA, APBA-sCy5, on the cell surface was larger than that of the smallest polymer chain, P1. Considering the peptidoglycan mesh structure of the B. subtilis cell surface and the relative hydrodynamic volume of the aggregated polymers (Fig. 3c), we speculate that the polymers are more likely to interact with the exposed diol motifs on the cell surface, whereas the monomeric form of APBA is more likely to penetrate the peptidoglycan mesh structure and label the inner part of the cell wall.

\section{Polymers with APBA repeating units detach from to $B$. subtilis cell surface upon addition of competitive diols.}

We found that the polymers P1, P2 and P3 can be readily detached from the cell surface by adding exogenous diols, analogous to molecular Velcro, whereas the monomeric APBA did not show this behavior. Upon adding exogenous diol species, boronate esters can undergo competitive 
exchange reactions (Fig. 4a). We supplemented selected diols in PBS suspension of labeled cells with monomeric APBA (Fig. 2c) or the polymers (Figs. 3h-j). After 6 hours of incubation with fructose, the fluorescence on the cell surface was diminished in mixtures of P1, P2, or P3 molecules and B. subtilis, indicating that the polymers bound to the cell surface were readily detached upon competitive diol exchange at the boronate ester linkage (Figs. 4e-g). Noteworthy is that the large cellular aggregates observed in the mixture of $\mathrm{P} 3$ and $B$. subtilis were completely dissociated into single cells upon fructose treatment (Figs. $4 \mathrm{~d}$ and $4 \mathrm{~g}$ ). This change was accompanied by a nearcomplete diminishment of the fluorescence signal on the cell surface. The bulk fluorescence measurements of these mixtures showed a greater than $90 \%$ reduction in fluorescence intensity upon addition of fructose compared to the initial point and supported our observations in fluorescence microscopy (Figs. 4i-k and Supplementary Figs. 28-31). We also found that common monosaccharides, glucose and sorbitol, could exert a similar effect to the bound polymers to the cells, evidenced by decrements in fluorescent intensity on the cell surface (Supplementary Figs. 19-20) as well as in bulk fluorescence measurements (Figs. 4i-k and Supplementary Figs. 28-31). The effectiveness of sugars for dissociating polymer/cell complexes follows the general order of fructose $\approx$ sorbitol $>$ glucose. Since both glucose and fructose can exist in furanose and pyranose forms ${ }^{21}$ fructose shows a higher binding affinity to phenylboronic acid species than glucose because the highest binding affinity isomer, $\beta$-D-fructofuranose, accounts for $25 \%$ of the total fructose in ambient conditions. ${ }^{22-23}$ In contrast, the highest binding affinity form of glucose is only $0.14 \%$ of the total glucose. The apparent association constants of APBA determined by Sumerlin and colleagues are $350 \mathrm{M}^{-1}$ for fructose, $610 \mathrm{M}^{-1}$ for sorbitol, and $8.1 \mathrm{M}^{-1}$ for glucose. ${ }^{24}$ Our results show fructose is similar to or slightly more effective than sorbitol in detaching bound polymers from B. subtilis surface, which may be due to the macromolecular nature of the polymers and 
teichoic acids on the cell surface. It is also worthwhile to note that $B$. subtilis uses glucose as the primary carbon source for its metabolism. ${ }^{25-26}$ When glucose is added to the polymer/cell complex (Figs. 4i-k and Supplementary Fig. 19), the cell surface fluorescence increases from 3 hours to 6 hours of incubation. This result suggests that consumption of externally added glucose limits the duration of effect. In contrast to the results of P1-P3 polymers, in the case of the bound monomeric APBA molecule (APBA-sCy5) to the cell, adding exogenous diols did not significantly reduce the fluorescence (Fig. 4h). This result corroborates our earlier speculation that the monomeric form of APBA is more likely to penetrate the peptidoglycan mesh structure and label the inner part of the peptidoglycan cell wall. Even with the same APBA binding motif, the bound polymers would be readily detached because their binding sites are more exposed to the surface. On the other hand, dissociation of the bound monomeric APBA residing deeper in the peptidoglycan network would experience more physical barriers to this exchange reaction.

\section{Designed telechelic block copolymers yield self-standing hydrogel upon mixing with $B$. subtilis.}

On the basis of our findings that APBA-containing synthetic macromolecules form a dynamic covalent interface with $B$. subtilis cell, we designed and synthesized telechelic block copolymers. They comprise hydrophilic polyethylene glycol (PEG) mid-block and end blocks containing APBA repeating units, and the mid-block size was varied from 4,000 g/mol to 20,000 g/mol (Fig. 5a). Since the mid-block PEG is known to swell in an aqueous environment, this telechelic design was expected to yield macroscopic soft materials crosslinking B. subtilis cells. GPC (Fig. 5b) of the reaction mixture showed curves corresponding to molecular weights of $9,369 \mathrm{~g} / \mathrm{mol}$ for T1, $16,740 \mathrm{~g} / \mathrm{mol}$ for $\mathrm{T} 2$, and $27,928 \mathrm{~g} / \mathrm{mol}$ for $\mathrm{T} 3$ (Fig. 5c). These results were in reasonable agreement with the ${ }^{1} \mathrm{H}$ NMR results (Supplementary Figs. 12-17). 
While solutions of these telechelic block copolymers alone are viscous liquids (Fig. 5e, see supplementary methods), addition of B. subtilis cells yields self-standing hydrogels (Figs. 5d and 5f). This confirms our expectation of creating a 3-dimensional network of living cells and telechelic polymers and highlights that both components are critical for the formation of hydrogels. Macroscopically, these hydrogels are self-standing, hold their shape, and are moldable. They can be easily fabricated and molded into desired shapes and sizes (Figs. 5g and 5h). Linear rheological measurements of a PBS solution of $\mathrm{T} 1, \mathrm{~T} 2$, and $\mathrm{T} 3$, in the presence and absence of $B$. subtilis cells, show that adding cells to these polymers increases the storage moduli by several orders of magnitude (Fig. 5i, Supplementary Fig. 37). These results strongly indicate that the dynamic covalent bond formation between the telechelic block copolymer and the cell surface is the driving force for gelation, and B. subtilis cells served as a crosslinker for this hydrogel network. These living materials exhibited larger storage moduli than the loss moduli over the entire range of frequencies examined (Fig. 5j). Telechelic block copolymers containing a larger PEG mid-block would have a lower concentration of chains per unit volume at a given mass concentration. In agreement with the rheological behavior of associative telechelic protein hydrogels reported by Tirrell and co-workers, ${ }^{27}$ the magnitude of the plateau storage moduli of these living materials decreases with the increasing mid-block size (Fig. 5j).

\section{Programming living materials with genetically engineered $B$. subtilis.}

With this novel platform, we demonstrated that engineering the B. subtilis component can yield materials capable of overproduction and elution of proteins, as well as biosensing. We engineered B. subtilis cells to express RFP with an N-terminal secretion sequence AmyQ so that newly synthesized RFP can be exported in extracellular space via secretion. ${ }^{28}$ Living materials comprising this engineered B. subtilis were immersed in LB media and incubated at $37^{\circ} \mathrm{C}$ for 96 
hours (Fig. 6a). Fluorescence intensities of these hydrogels from RFP production increased over time (Fig. 6b and Supplementary Fig. 35). It is notable that optical densities of supernatants at 600 $\mathrm{nm}\left(\mathrm{OD}_{600}\right)$ consistently remain below 0.5 (Fig. 6c, black). Considering inoculation of a small number of cells in nutrient-rich media results in exponential growth and turbid saturated culture $\left(\mathrm{OD}_{600}>1\right)$, this result suggests that the telechelic block copolymers effectively entrap cells in a nutrient-rich environment for 96 hours. The fluorescence intensities of the collected supernatant show a gradual increase over 96 hours (Fig. 6c, red). Interestingly, the fluorescence emission of the hydrogels plateau around 30 hours, after which we observe a rapid increase in fluorescence intensity from the supernatant, presumably because the polymeric network serves as a diffusion barrier of secreted RFP proteins. This result shows that we can program living materials to produce and release recombinant proteins while achieving effective cellular confinement. Next, we produced biosensor living materials with engineered $B$. subtilis cells expressing green fluorescent proteins in response to small-molecule inducers such as cumic acid (Supplementary Figs. 32a and $32 \mathrm{~b}$ ) or isopropyl $\beta$-D-1-thiogalactopyranoside (IPTG, Supplementary Figs. 32c and 32d). These materials were immersed in LB media with or without appropriate inducers (100 $\mu \mathrm{M}$ cumic acid or $1 \mathrm{mM} \mathrm{IPTG).} \mathrm{The} \mathrm{hydrogels} \mathrm{incubated} \mathrm{with} \mathrm{inducers} \mathrm{showed} \mathrm{higher} \mathrm{fluorescent} \mathrm{intensities} \mathrm{for}$ both cases (Figs. 6d-g, 6i-1). However, the cumic acid-inducible system showed a more robust fold change (Fig. 6h) than the IPTG-inducible system (Fig. 6m). Because IPTG bears a cis-diol structure, we speculate that it directly interacts with boronic acid moiety in the polymer chains, and its intracellular concentration is lower than in the case of cumic acid.

\section{B. subtilis cells encased in polymeric living material can be retrieved and analyzed upon exposure to competitive diol species.}


The novel design of these materials allows on-demand retrieval of cells upon immersing in solutions containing fructose, enabled by the diol-exchange reaction at APBA binding sites (Fig. 7a). The ability to retrieve cells from materials for biological analysis opens new possibilities for understanding how immobilization and confinement affect various aspects of cellular phenotype, gene expression, and metabolism. Living materials, which were prepared by mixing a PBS solution of T1 and a suspension of B. subtilis cells, were immersed in PBS in the absence (Figs. 7b-d, left) and presence (Figs. 7b-d, right) of fructose. In just 30 minutes, the supernatant of the materials treated with fructose turned opaque, indicating the release of the encased cells (Fig. 7c, right). After 16 hours, the materials immersed in fructose solution were completely dissolved, whereas the materials immersed in PBS without fructose remained as swollen networks of polymers and living cells. As the fructose solution is an incomplete medium that does not permit cell growth (Supplementary Fig. 38), monitoring cell density of the resulting supernatant through the absorbance measurements at $600 \mathrm{~nm}\left(\mathrm{OD}_{600}\right)$ reflects the number of cells that become freed from the polymeric network. We observed a gradual increase in $\mathrm{OD}_{600}$ in both cases, but the $\mathrm{OD}_{600}$ values of the PBS solution that contains fructose were significantly higher than that of the PBS solution without fructose (Fig. 7e). By comparison to a control solution containing the same number of cells used in forming the material, we determined that $65 \%$ of cells were retrieved from this hydrogel upon the fructose treatment. We investigated the cell viability of the retrieved cells using a 5-cyano-2,3-ditolyl tetrazolium chloride (CTC) reagent, which has been used to estimate the respiratory activity of the bacterial cells. The cells released from the living materials showed similar metabolic activity (88\%) compared to the control (Fig. 7f, Supplementary Fig. 33).

The ability to readily dissociate these living materials enabled us to accurately quantify the degree of sporulation even deep within the material. To carefully monitor the fraction of mature 
spores and vegetative cells within living materials, we constructed a dual fluorescence strain of $B$. subtilis that expresses mWasabi fused to the C-terminal of a spore coat protein CotG, and RFP under the promotor $\mathrm{P}_{\text {veg }}$, which is active during vegetative growth (Fig. 7g) The vegetative cells and matured spores of this strain are easily identified through the emission of fluorescence signals (Supplementary Figs. 22 and 23). The vast majority of B. subtilis at the beginning only expressed intracellular RFP (Fig. 7h). In contrast, after $48 \mathrm{~h}$ immersion in sporulation media, approximately $40 \%$ of the detected fluorescent particles were spores (Fig. 7i). We compared the degree of sporulation of $B$. subtilis confined within materials over time with the control sample, which contains the same number of free-floating cells in sporulation media. Encased B. subtilis forms spores at a slightly attenuated rate at the beginning but reaches a similar number to that of the control in $48 \mathrm{~h}(\sim 40 \%)$ (Figs. $7 \mathrm{j})$.

\section{CONCLUSION}

In this work, we report the first demonstration of programmable living materials constructed with a dynamic covalent interface between synthetic telechelic block copolymers and engineered B. subtilis cells. This development was made possible by our finding that 3acetamidophenylboronic acid (APBA) and APBA-containing polymers form dynamic covalent bonds with available diols on the $B$. subtilis cell surface, and the polymer binding to $B$. subtilis shows a multivalent effect with complete reversibility upon adding competitive diol species. Given the rapidly-growing toolbox of synthetic biology and expanding interest in its use in addressing challenges in medicine, sensing, sustainability, and defense, we envision this work will expand the scope of functional biomaterials by opening possibilities for integrating emergent cellular functionalities into the design of high-performance polymeric materials. In addition, due to the 
dynamic covalent interface, the living cells encased in these materials can be retrieved upon exposure to solutions containing competitive diol species, allowing us to perform detailed biological analyses. In this regard, this work also establishes the critical groundwork of a future platform we envision for understanding the biology of cells confined within materials by allowing transcriptomic or proteomic analyses. 


\section{METHODS}

Bacterial growth conditions. Pre-cultures of $B$. subtilis and E. coli were prepared by inoculating a single colony in Lysogeny broth (LB) at $37{ }^{\circ} \mathrm{C}$ and growing for 14 hours. RFP-expressing $B$. subtilis carrying an antibiotic resistance marker were selected by supplementing the growth medium with chloramphenicol $(5 \mu \mathrm{g} / \mathrm{ml})$. Cumic acid-inducible $B$. subtills were prepared by inoculating a single colony in $\mathrm{LB}$ containing spectinomycin $(100 \mu \mathrm{g} / \mathrm{ml})$ at $37^{\circ} \mathrm{C}$ and growing for 14 hours.

Genetic construction of $\boldsymbol{B}$. subtilis. All genetic manipulations were carried out in E. coli and sequenced. Verified constructs were subsequently transformed into B. subtilis (PY79). Chromosomal expression of RFP was achieved by integrating $\mathrm{P}_{\mathrm{veg}}$-mrfp into amyE locus with vector $\mathrm{pBS1C}$. The sequence of mrfp along with the double transcriptional terminators was amplified directly from pBS1C with primer YH120 (GATCGgtCTCAGgtGgtgaAtACTAGATGGCTTCCTCCGAAGA) and YH108 (GATCGCATGCTATAAACGCAGAAAGGCCCAC). Chromosomal expression of AmyQ-RFP was achieved by integrating $\mathrm{P}_{\mathrm{veg}}$-amyq-mrfp into amyE locus with vector pBS1C. The sequence of the secretion signal peptide, AmyQ was amplified from vector pHT43 with primer YH134 (GATCGGTCTCAGGTGGTGAATACTAGATGATTCAAAAACGAAAGCG) and YH135 (GATCGGTCTCTACGGCTGATGTTTTTG), digested with EcoRI and BsaI prior to ligation. Chromosomal co-expression of mWasabi and RFP was achieved by integrating $\mathrm{P}_{\mathrm{veg}}$-mrfp and cotG-mWasabi into amyE and lacA locus using vector pBS1C and pBS2E, respectively into the genome of PY79. The sequence of cotG along with its endogenous promoter and ribosomal binding regions was amplified from PY79 genome using primer YH178 $\begin{array}{llll}\text { (AAAAAGAATCTTGATTACCTTCATCACAGCTG) and } & \text { YH180 }\end{array}$ 
(GATCGGTCTCCTCCACCTTTGTATTTCTTTTTGACTACCCAGCA). The IPTG-inducible construct was based on a previously reported $\mathrm{T} 7$ circuit. ${ }^{29}$ The gene encoding $\mathrm{P}_{\mathrm{T} 7 \mathrm{Lacl}}-\mathrm{Sfgfp}$ was amplified with primers YH338 (GATCGGATCCTATAGATTTCATTTGGCTTCTAAATT) and YH339 (GATCACTAGTAACTCATTATTTGTACAGTTCATCCATA). The PCR product was then digested with BamHI and SpeI and ligated into the PBS1C vector. The $\mathrm{P}_{\text {hyperspank-T7RNAP- }}$ $\begin{array}{lllll}\mathrm{P}_{\text {penB }} \text {-lacI fragment was amplified using primers } & \text { YH290 }\end{array}$ (GATCGAATTCGGTAAATGTGAGCACTCACAATT) and YH291 (GATCACTAGTTAACTCACATTAATTGCGTTGCG). After digestion with EcorI and SpeI, the fragment was inserted into the PBS4S vector, which confers spectinomycin resistance and integrates into the thrC locus. The SpoVG ribosomal binding site was cloned downstream of the promoter with standard BioBrick RFC spacers. Purified plasmids were linearized by digesting with SacI before transformation.

Fluorescence microscopy of APBA monomer or polymer bound cells. Phosphate buffered saline (PBS) suspensions of $B$. subtilis of $E$. coli cells were treated with a PBS solution of APBAsCy5 or Tris-sCy5 at $25{ }^{\circ} \mathrm{C}$ for 3 hours. After washing with PBS, the cell suspensions were subjected to fluorescence microscopy $\left(\lambda_{\mathrm{ex}}=630 \mathrm{~nm}\right)$.

Quantification of bound APBA-based monomeric or polymeric molecules to B. subtilis cells. The suspensions of $B$. subtilis $\left(\mathrm{OD}_{600}=2.3\right)$ were mixed with PBS solution $(20 \mathrm{mM}, \mathrm{pH} 7.4)$ of APBA-sCy5 $(15 \mu \mathrm{M})$ or Tris-sCy5 $(15 \mu \mathrm{M})$, and the resulting mixtures were incubated for 3 hours at room temperature. The suspensions of $B$. subtilis $\left(\mathrm{OD}_{600}=2.3\right)$ were mixed with PBS solution (20 mM, pH 7.4, 5\% MeOH) of $\mathrm{P} 1, \mathrm{P} 2$, or $\mathrm{P} 3(15 \mu \mathrm{M})$, and the resulting mixtures were incubated for 3 hours at room temperature. The cell samples were washed with PBS twice and subjected to fluorescence microscopy $\left(\lambda_{\mathrm{ex}}=630 \mathrm{~nm}\right)$. The numbers of cell-bound APBA-sCy5 or P1-P3 
molecules $(n)$ in a suspension were estimated according to a calibration curve (fitted by simple linear regression) from the fluorescence intensity at $670 \mathrm{~nm}$. Colony-forming unit (CFU) assays were performed to the original cell suspension to calculate the number of cells $\left(n_{\mathrm{c}}\right)$ added to each sample. The number of molecules per cell was deduced by dividing $n$ by $n_{\mathrm{c}} . N=3$ (biological replicates). Error bars represent \pm s.e.m.

CFU assay. For cell culture, aliquots of overnight culture grown in LB were diluted in PBS with a factor that generated between 10 to 100 colonies on LB agar plates. Colonies were subsequently counted and averaged among two or three biological replicates.

Sugar reversibility. To PBS suspensions (20 mM, pH 7.4) of B. subtilis treated with APBA-sCy5 or $\mathrm{P} 1-\mathrm{P} 3$ were added an aqueous solution of fructose, sorbitol, or glucose $(50 \mathrm{mM})$. These mixtures were agitated $(800 \mathrm{rpm})$ at $30{ }^{\circ} \mathrm{C}$. After rinsing with PBS, the cell suspensions were subjected to fluorescence microscopy $\left(\lambda_{\mathrm{ex}}=630 \mathrm{~nm}\right)$ and bulk fluorescence measurements. The relative fluorescence intensities at a given time were calculated from $\left(I_{\mathrm{t}} / I_{0}\right) \times 100(\%)$, where $I_{\mathrm{t}}$ is the FL intensity at $670 \mathrm{~nm}$ observed after addition of exogenous diol overtime $(\mathrm{t}=1,3$, and $6 \mathrm{~h})$, and $I_{0}$ is the $670 \mathrm{~nm}$ FL intensity at time 0 , respectively. $N=3$ (biological replicates). Error bars represent \pm s.e.m.

\section{Hydrogel preparation:}

T1 living materials: T1 $(10 \mathrm{mg})$ was dissolved in $\mathrm{NaOH}(1 \mathrm{M}, \mathrm{pH} 13,57 \mu \mathrm{L})$ and diluted with doubly distilled water (71 $\mu \mathrm{L})$. PBS $(0.2 \mathrm{M}, \mathrm{pH} 7.0,20 \mu \mathrm{L})$ was added to the resulting solution, and the mixture was sonicated for $30 \mathrm{~min}(\times 3)$, affording a clear solution $(\mathrm{pH}=9.5)$. To this polymer solution $(150 \mu \mathrm{L})$ was added a suspension of $B$. subtilis $\left(5.0 \times 10^{10}\right.$ cells $\left./ \mathrm{mL}, 100 \mu \mathrm{L}\right)$, and the resulting mixture was vortexed for $1 \mathrm{~min}$, affording a pale-yellow hydrogel. We note that preparation of the high concentration ( $>3 \mathrm{wt} \%$ ) of the telechelic block copolymers in a PBS buffer 
is important for gelation. If a polymer solution of $3 \mathrm{wt} \%$ (or less) is used, it results in a turbid suspension.

T2 living materials: T2 (30 mg) was dissolved in $\mathrm{NaOH}(1 \mathrm{M}, \mathrm{pH} 13,80 \mu \mathrm{L})$ and diluted with doubly distilled water $(93 \mu \mathrm{L})$. PBS $(0.2 \mathrm{M}, \mathrm{pH} 7.0,20 \mu \mathrm{L})$ was added to the resulting solution, and the mixture was sonicated for $30 \mathrm{~min}(\times 6)$, affording a clear solution $(\mathrm{pH}=9.4)$. To this polymer solution $(150 \mu \mathrm{L})$ was added a suspension of $B$. subtilis $\left(5.0 \times 10^{10}\right.$ cells $\left./ \mathrm{mL}, 100 \mu \mathrm{L}\right)$, and the resulting mixture was vortexed for $1 \mathrm{~min}$, affording a pale-yellow hydrogel. We note that preparation of the high concentration (>3 wt\%) of the telechelic polymers in a PBS buffer is important for gelation. If a polymer solution of $3 \mathrm{wt} \%$ (or less) is used, it results in a turbid suspension.

T3 living materials: $\mathrm{T} 3(30 \mathrm{mg})$ was dissolved in $\mathrm{NaOH}(1 \mathrm{M}, \mathrm{pH} 13,85 \mu \mathrm{L})$ and diluted with doubly distilled water $(91.5 \mu \mathrm{L})$. PBS $(0.2 \mathrm{M}, \mathrm{pH} 7.0,20 \mu \mathrm{L})$ was added to the resulting solution, and the mixture was sonicated for $30 \mathrm{~min}(\times 6)$, affording a clear solution $(\mathrm{pH}=9.6)$. To this polymer solution $(150 \mu \mathrm{L})$ was added a suspension of $B$. subtilis $\left(5.0 \times 10^{10}\right.$ cells $\left./ \mathrm{mL}, 100 \mu \mathrm{L}\right)$, and the resulting mixture was vortexed for $1 \mathrm{~min}$, affording a pale-yellow hydrogel. We note that preparation of the high concentration ( $>3 \mathrm{wt} \%$ ) of the telechelic polymers in a PBS buffer is important for gelation. If a polymer solution of $3 \mathrm{wt} \%$ (or less) is used, it results in a turbid suspension.

Rheological characterizations. Rheology measurements were performed on a Discovery series HR-2 hybrid rheometer from TA instruments with a $25 \mathrm{~mm}$ diameter parallel plate geometry. Amplitude sweep measurements were conducted at an angular frequency of $3 \mathrm{rad} / \mathrm{s}$ at $25{ }^{\circ} \mathrm{C}$. Frequency sweep measurements were performed with a shear stress of $1 \%$ for living materials and $50 \%$ for polymer solutions in the angular frequency of 100 to $0.1 \mathrm{rad} / \mathrm{s}$ at $25^{\circ} \mathrm{C}$. 
Preparation and characterization of RFP-releasing living materials. Living materials comprising T1 $(150 \mu \mathrm{L})$ and RFP-secreting B. subtilis $\left(5.0 \times 10^{10}\right.$ cells $\left./ \mathrm{mL}, 100 \mu \mathrm{L}\right)$ was immersed in LB media (3 mL) over $96 \mathrm{~h}$ at $37^{\circ} \mathrm{C}$. The supernatant LB media $(50 \mu \mathrm{L})$ were collected and subjected to fluorescence measurements $\left(\lambda_{\mathrm{ex}}=530 \mathrm{~nm}, \lambda_{\mathrm{obs}}=605-670 \mathrm{~nm}\right)$. The fluorescence intensities at a given time were corrected by subtracting the fluorescence of LB media as a baseline. The materials were subjected to the ChemiDoc imaging system $\left(\lambda_{\mathrm{ex}}=520-545 \mathrm{~nm}, \lambda_{\mathrm{obs}}=577-613\right.$ $\mathrm{nm}$ ) and the image fluorescence was calculated by ImageJ. $N=3$ (biological replicates). Error bars represent \pm s.e.m.

\section{Preparation and characterization of inducible living materials:}

Cumic acid-inducible living materials comprising T1 $(150 \mu \mathrm{L})$ and cumic acid-inducible $B$. subtilis $\left(5.0 \times 10^{10}\right.$ cells $\left./ \mathrm{mL}, 100 \mu \mathrm{L}\right)$ was immersed in LB media $(1 \mathrm{~mL})$ containing cumic acid $(100 \mu \mathrm{M})$ for $24 \mathrm{~h}$ at $37^{\circ} \mathrm{C}$. After rinsing with PBS $(500 \mu \mathrm{L})$, the hydrogel was subjected to the ChemiDoc imaging system $\left(\lambda_{\mathrm{ex}}=520-545 \mathrm{~nm}, \lambda_{\mathrm{obs}}=577-613 \mathrm{~nm}\right)$, and the image fluorescence was calculated by ImageJ. $N=3$ (biological replicates). Error bars represent \pm s.e.m.

IPTG-inducible living materials comprising T1 $(150 \mu \mathrm{L})$ and IPTG-inducible $B$. subtilis $(5.0 \times$ $10^{10}$ cells $\left./ \mathrm{mL}, 100 \mu \mathrm{L}\right)$ was immersed in LB media $(1 \mathrm{~mL})$ containing IPTG $(1 \mathrm{mM})$ for $24 \mathrm{~h}$ at 37 ${ }^{\circ} \mathrm{C}$. After rinsing with PBS $(500 \mu \mathrm{L})$, the hydrogel was subjected to the ChemiDoc imaging system $\left(\lambda_{\text {ex }}=520-545 \mathrm{~nm}, \lambda_{\text {obs }}=577-613 \mathrm{~nm}\right)$, and the image fluorescence was calculated by ImageJ. $N$ $=3$ (biological replicates). Error bars represent \pm s.e.m.

Retrieving cells from living materials. Living materials were immersed in PBS solutions containing fructose $(100 \mathrm{mM})$ and mechanically agitated $(200 \mathrm{rpm})$ at $30{ }^{\circ} \mathrm{C}$.

Cell viability test. The cell suspensions $\left(1 \mathrm{~mL}, \mathrm{OD}_{600}=0.1\right)$ was incubated with an aqueous solution of 5-cyano-2,3-ditolyl tetrazolium chloride (CTC; $50 \mathrm{mM}, 100 \mu \mathrm{L})$ from BacLight $^{\mathrm{TM}}$ 
RedoxSensor ${ }^{\mathrm{TM}} \mathrm{CTC}$ viability kit for $30 \mathrm{~min}$ at $37^{\circ} \mathrm{C}$. After rinsing with PBS $(100 \mu \mathrm{L})$ twice, the cell suspensions were subjected to fluorescence spectroscopy $\left(\lambda_{\mathrm{ex}}=450 \mathrm{~nm}\right) . N=3$ (biological replicates). Error bars represent \pm s.e.m.

Quantification of spores upon in situ sporulation. Living materials comprising T1 (150 $\mu \mathrm{L})$ and dual fluorescent $B$. subtilis $\left(5.0 \times 10^{10}\right.$ cells $\left./ \mathrm{mL}, 100 \mu \mathrm{L}\right)$ were immersed in sporulation media $(1$ $\mathrm{mL}$ ) at $37^{\circ} \mathrm{C}$, over $48 \mathrm{~h}$. The hydrogels were transferred to an aqueous solution containing fructose $(100 \mathrm{mM})$ and mechanically agitated in sporulation media containing fructose $(100 \mathrm{mM})$ at $30{ }^{\circ} \mathrm{C}$ for 1 hour. Supernatants were subjected to fluorescence microscopy $\left(\lambda_{\mathrm{ex}}=488, \lambda_{\mathrm{obs}}=525-575 \mathrm{~nm}\right.$ for $\mathrm{mWasabi}$ and $\lambda_{\mathrm{ex}}=530, \lambda_{\mathrm{obs}}=605-670$ for RFP). $N=3$ (biological replicates). Error bars represent \pm s.e.m. 


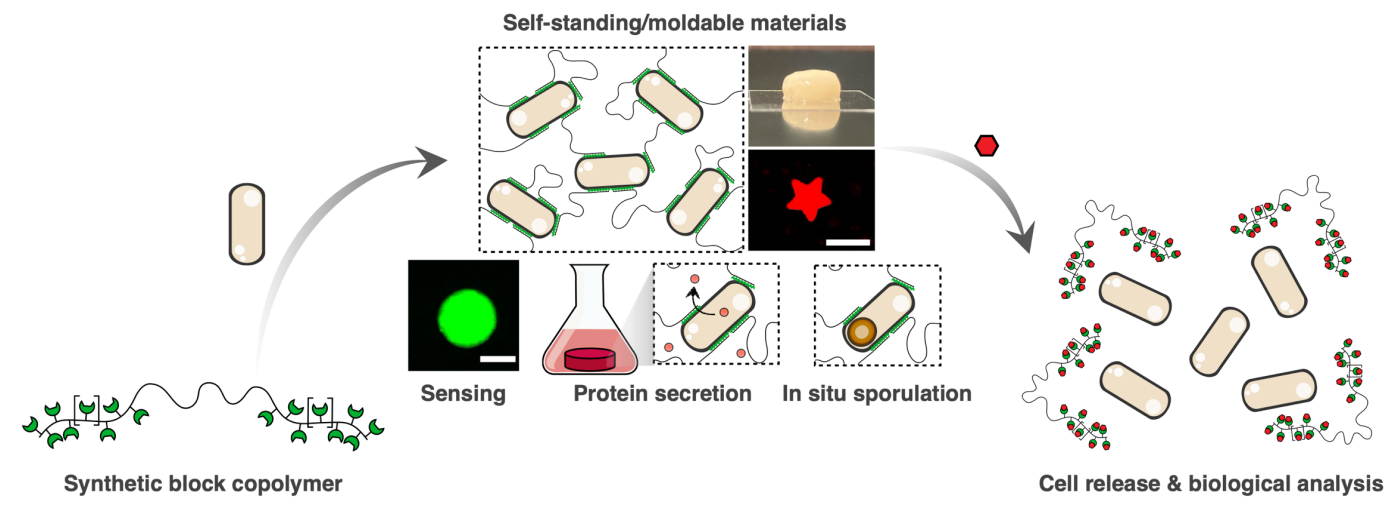

Figure 1. Dynamic covalent bond formation between engineered B. subtilis cells and synthetic block copolymer yields self-standing and moldable living materials equipped with functionalities such as sensing, protein secretion, and in situ sporulation. As the interaction between polymers and living cells is dynamic and reversible, encased living cells can be released upon immersing the material in a solution containing competitive diols and further be subjected to biological analyses. 

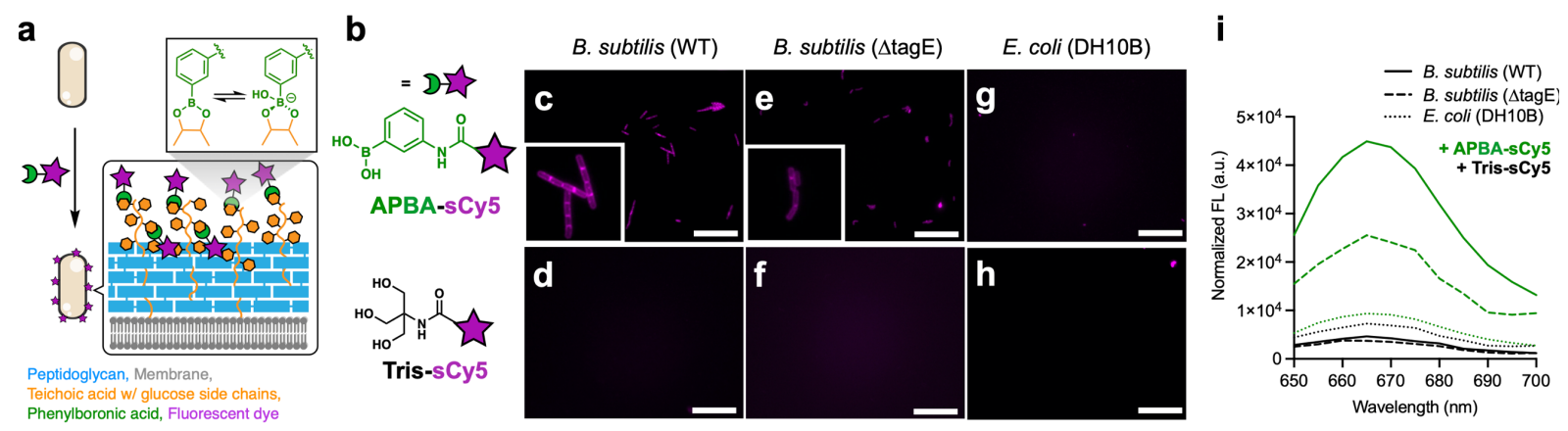

Figure 2. 3-Acetamidophenylboronic acid (APBA) binds to B. subtilis cell surface. (a) Schematic illustration of the binding of APBA-sCy5, bearing APBA motif and a fluorescent dye sulfo-cyanine 5 (sCy5), to glucose side chains of the wall teichoic acids on the surface of B. subtilis. (b) Molecular structures of APBA-sCy5 and Tris-sCy5. (c-h) Representative fluorescence microscope $\left(\lambda_{\text {ex }}=630 \mathrm{~nm}\right.$, $\lambda_{\text {obs }}=690-740 \mathrm{~nm}$ ) images of wild type (PY79 laboratory strain, abbreviated as WT), tagE-deletion mutant $(\Delta \operatorname{tagE}) B$. subtilis cells and E. coli cells (DH10B) after 3-hour incubation at room temperature with fluorescent probes. (c) APBA-sCy5 with B. subtilis WT, (d) Tris-sCy5 with B. subtilis WT, (e) APBA-sCy5 with B. subtilis $\Delta \operatorname{tagE}$, (f) Tris-sCy5 with B. subtilis $\Delta \operatorname{tagE}$, (g) APBA-sCy5 with $E$. coli, and (h) Tris-sCy5 with E. coli. The cells were incubated with a fluorescent probe $(15 \mu \mathrm{M})$ in PBS $(20$ $\mathrm{mM}, \mathrm{pH}$ 7.4) and washed with PBS twice. Scale bars $=20 \mu \mathrm{m}$. (i) Fluorescence spectra $\left(\lambda_{\mathrm{ex}}=630 \mathrm{~nm}\right)$ of B. subtilis WT (solid lines), B. subtilis $\Delta$ tagE (dotted lines), and E. coli DH10B (densely dotted lines) cells after 3-hour incubation at room temperature in PBS with APBA-sCy5 (green) and Tris-sCy5 (black). The cells were incubated with a fluorescent probe $(15 \mu \mathrm{M})$ in PBS $(20 \mathrm{mM}, \mathrm{pH} 7.4)$ and washed with PBS twice. The fluorescence intensities were normalized to the optical density (absorbance at 600 $\mathrm{nm}$ ) of each cell suspension. 


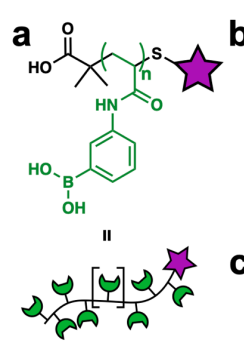

P1, P2, P3

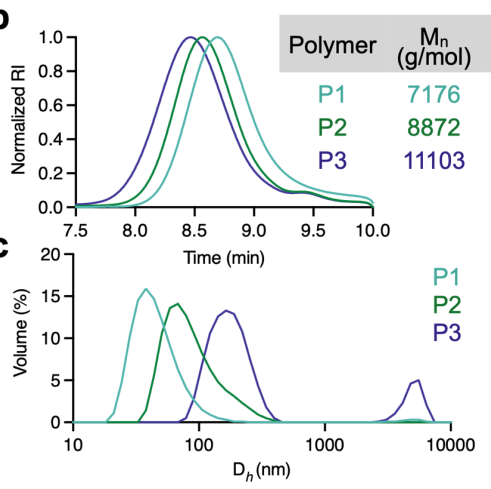

d
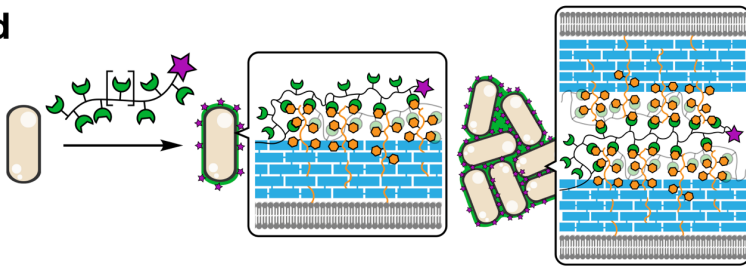

$\mathrm{P} 1$
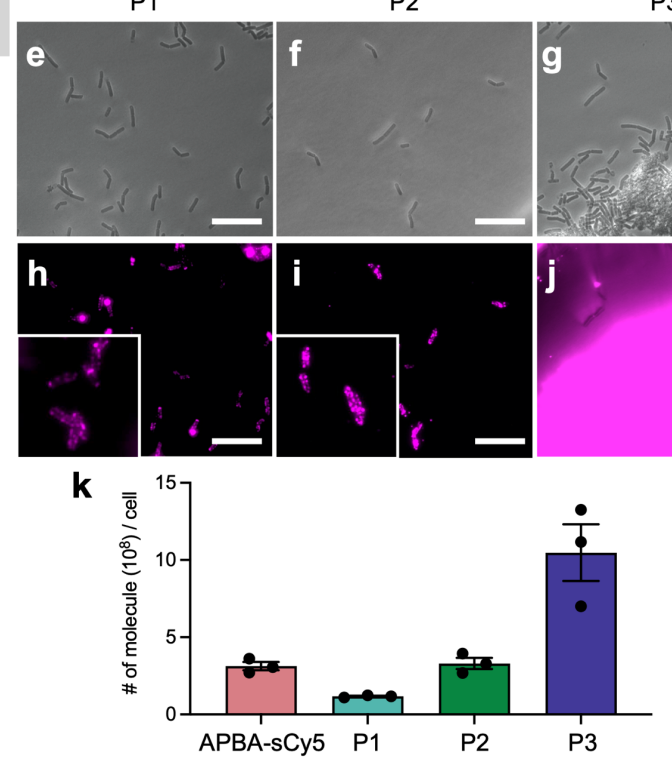

P3
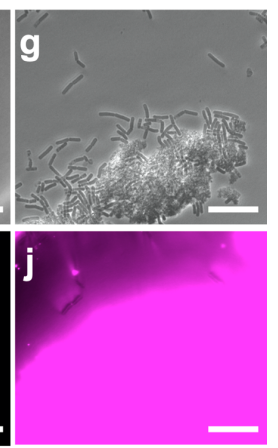

Figure 3. Polymers with APBA repeating units bind to $B$. subtilis cell surface and show a multivalent effect. (a) Molecular structure of polymers P1, P2, and P3. (b) Gel permeation chromatography (GPC) of polymers in DMF and a summary of experimental molecular weight and polydispersity index (PDI) based on the GPC data. (c) Dynamic light scattering histograms of polymers in $\mathrm{MeOH} /$ water (5/95). (d) Schematic illustration of the binding behaviors of APBA-containing polymers, $\mathrm{P} 1-\mathrm{P} 3$, to the $B$. subtilis cell surface. With the increasing number of the APBA repeating units, $B$. subtilis cells tend to form large cellular aggregates. (e-j) Bright-field and fluorescence microscope images $\left(\lambda_{\mathrm{ex}}=630 \mathrm{~nm}, \lambda_{\mathrm{obs}}=690-740 \mathrm{~nm}\right)$ of B. subtilis cells incubated with APBA-containing polymers. The upper panel shows representative bright-field images, and the lower panel represents fluorescence microscope images corresponding to them. (e \& h) P1, (f \& i) P2, and (g \& j) P3. Cells were incubated for 3 hours with polymer $(15 \mu \mathrm{M})$ in PBS $(20 \mathrm{mM}, \mathrm{pH} 7.4)$ and washed with PBS twice. Scale bars $=$ $5 \mu \mathrm{m}$. (k) Average number of APBA-sCy5, P1, P2, and P3 molecules per one B. subtilis cell. These values were calculated from the bulk fluorescence intensity and colony-forming unit of each cell suspension. See methods for details. $N=3$ (biological replicates). Error bars represent \pm s.e.m. 
a

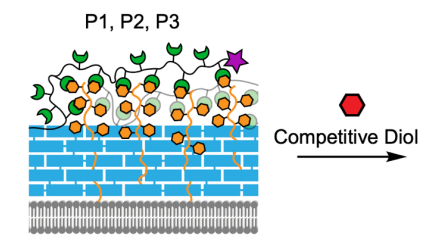

P1

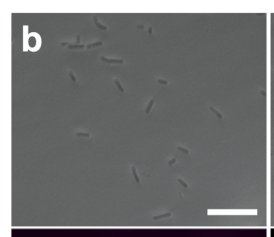

e

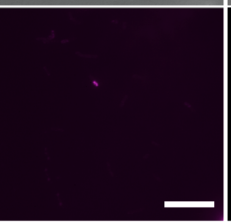

P2

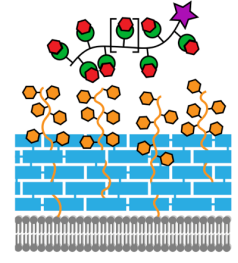

P3
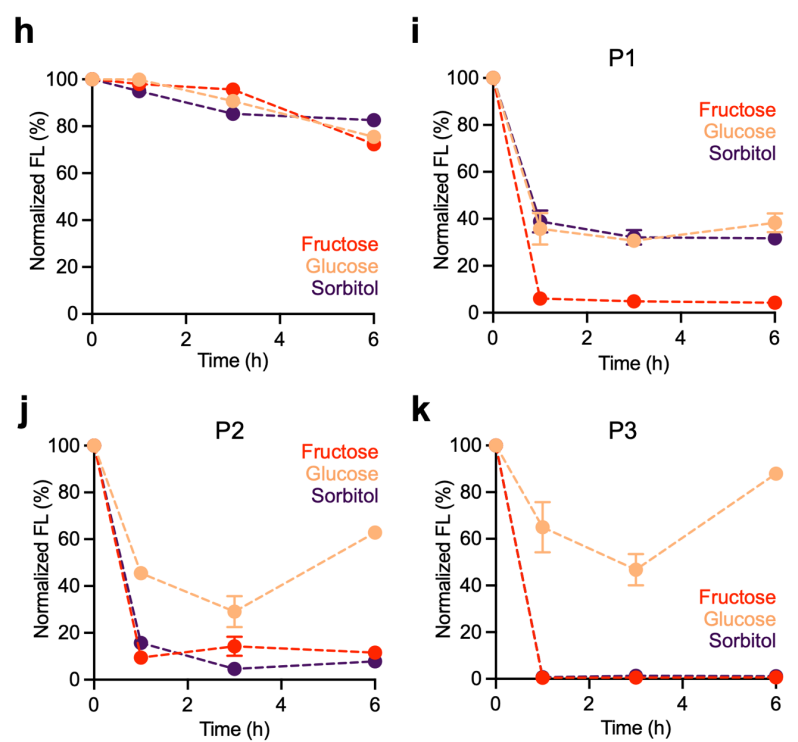

Figure 4. Polymers with APBA repeating units detach from to $B$. subtilis cell surface upon addition of competitive diols. (a) Schematic illustration of $\mathrm{P} 1-\mathrm{P} 3$ dissociating from the surface of $B$. subtilis cells in the presence of competing diols. (b-g) Bright-field and fluorescence microscope images ( $\lambda_{\text {ex }}=$ $630 \mathrm{~nm}, \lambda_{\text {obs }}=690-740 \mathrm{~nm}$ ) of $B$. subtilis cells incubated with the polymers for 3 hours, washed and subsequently treated with fructose $(50 \mathrm{mM})$ in PBS $(20 \mathrm{mM}, \mathrm{pH} 7.4)$ for 6 hours. The upper panel shows representative bright-field images, and the lower panel represents fluorescence microscope images corresponding to them. (b \& e) P1, (c \& f) P2, and (d \& g) P3. The cells were washed with PBS twice. Scale bars $=5 \mu \mathrm{m}$. (h-k) Normalized fluorescence profiles of $B$. subtilis cell suspension first incubated with (h) APBA-sCy5, (i) P1, (j) P2, or (k) P3 for 3 hours and subsequently treated with competing diols over 6 hours. $N=3$ (biological replicates). Error bars represent \pm s.e.m. 


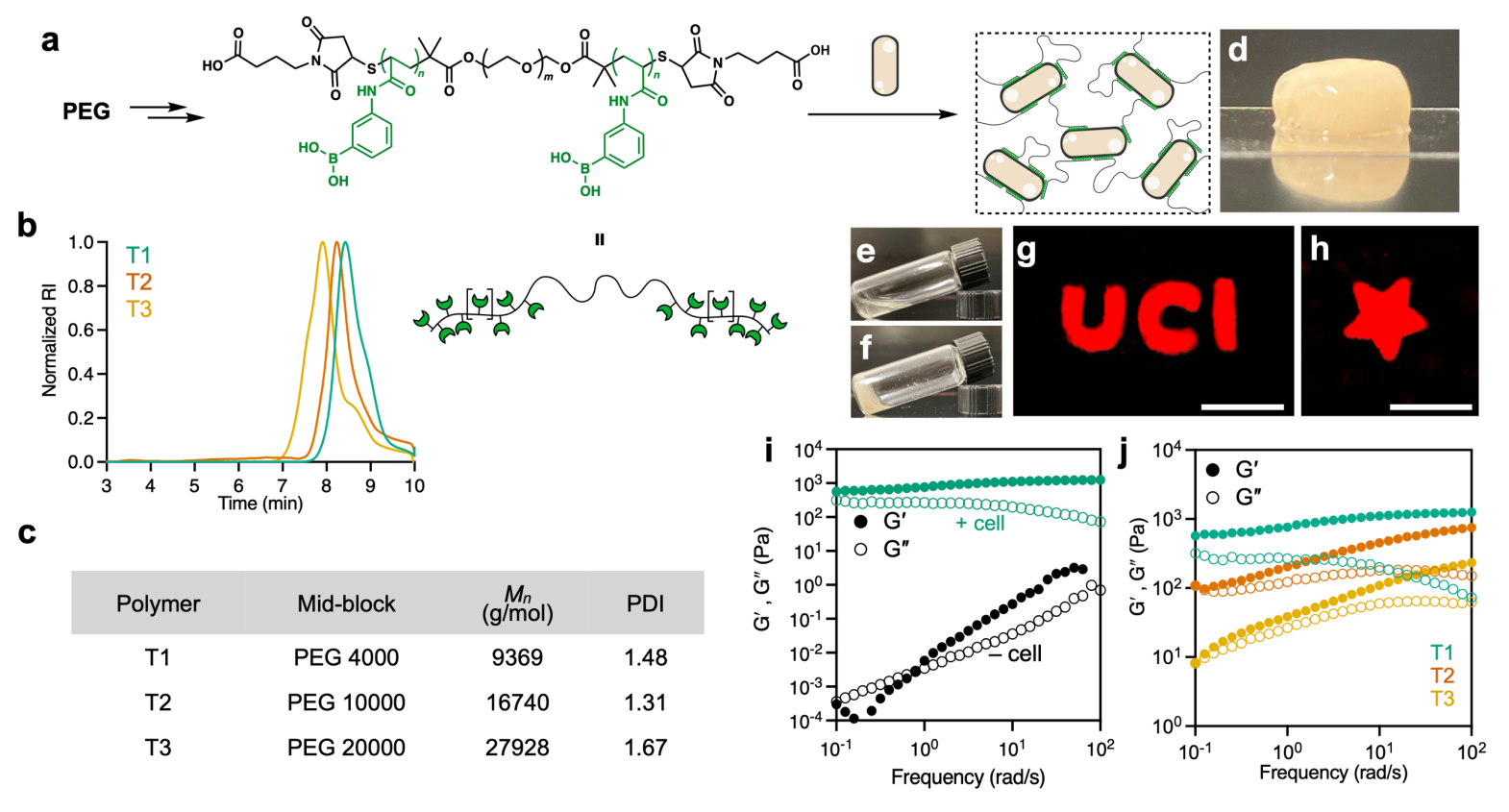

Figure 5. Telechelic polymers with APBA chain ends yield self-standing hydrogel upon mixing with B. subtilis. (a) Molecular structure of telechelic block polymers, T1-T3, bearing a polyethylene glycols mid-block (molecular weight: 4,000, 10,000, and 20,000 g/mol) and polymers of APBA at each end. Proposed mechanism for network formation in living materials. (b) GPC of T1-T3 in DMF. (c) A table of experimental molecular weight and polydispersity index (PDI) based on the GPC data. (d) An optical image of a self-standing hydrogel made with T1 and B. subtilis cells. (e-f) Optical images of a PBS buffer $(80 \mathrm{mM}, \mathrm{pH} 9.4)$ solution of $\mathrm{T} 1$ in the (e) absence and (f) presence of B. subtilis $\left(5.0 \times 10^{10}\right.$ cells $/ \mathrm{mL})$. $(\mathbf{g}-\mathbf{h})$ Fluorescence image $\left(\lambda_{\mathrm{ex}}=520-545 \mathrm{~nm}, \lambda_{\mathrm{obs}}=577-613 \mathrm{~nm}\right)$ of different shapes of hydrogels prepared by mixing T1 with engineered $B$. subtilis constitutively expressing RFP. Scale bars $=1 \mathrm{~cm}$. (i) Storage moduli $\mathrm{G}^{\prime}$ (filled circle) and loss moduli $\mathrm{G}^{\prime \prime}$ (open circle) of T1 in the absence (black, strain $=50 \%$ ) and the presence (green, strain $=1 \%$ ) of $B$. subtilis cells. $(\mathbf{j}) \mathrm{G}^{\prime}$ and $\mathrm{G}^{\prime \prime}$ values of living materials comprising T1, T2, or T3 with B. subtilis cells. 

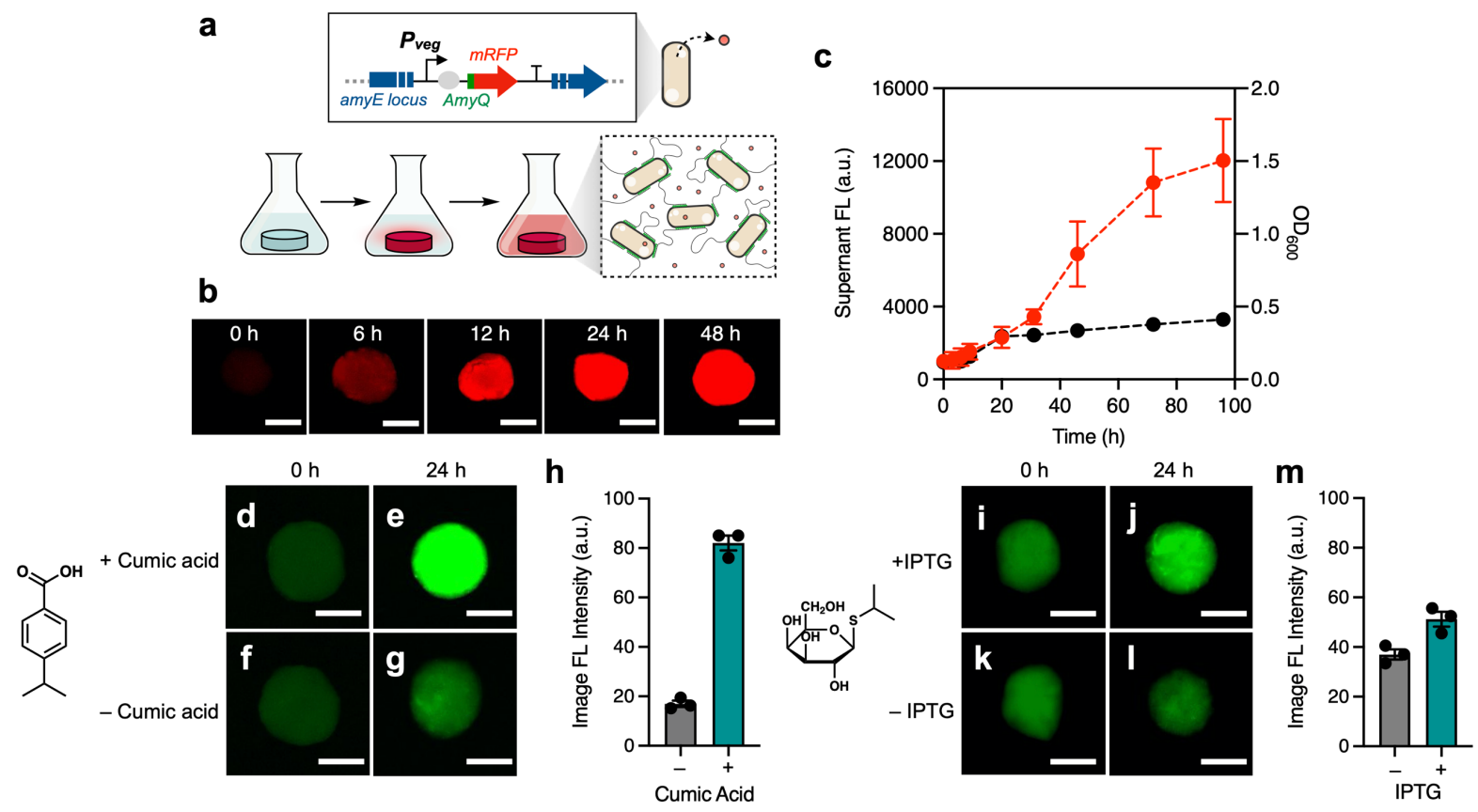

Figure 6. Programming living materials with genetically engineered $\boldsymbol{B}$. subtilis. (a) Schematic illustrations of genetic circuit design for engineered $B$. subtilis, programmed to secrete red fluorescent proteins (RFP) and elution of RFP from living material to medium. (b) Time-dependent fluorescence images $\left(\lambda_{\mathrm{ex}}=520-545 \mathrm{~nm}, \lambda_{\mathrm{obs}}=577-613 \mathrm{~nm}\right)$ of living materials comprising T1 and engineered $B$. subtilis secreting RFP (0-48 h). (c) The time-dependent changes in fluorescence intensities (red, $\lambda_{\mathrm{ex}}=$ $558 \mathrm{~nm}, \lambda_{\mathrm{em}}=580 \mathrm{~nm}$ ) and the optical density at $600 \mathrm{~nm}$ (black) of the medium where living materials are immersed $(0-96 \mathrm{~h}) .(\mathbf{d}-\mathbf{g})$ Fluorescence images $\left(\lambda_{\text {ex }}=520-545 \mathrm{~nm}, \lambda_{\text {obs }}=577-613 \mathrm{~nm}\right)$ of living materials comprising $\mathrm{T} 1$ and engineered $B$. subtilis that senses cumic acid and fluoresces. The hydrogel was immersed in LB media in the (d \& e) presence and (f $\boldsymbol{\&} \mathbf{g})$ absence of cumic acid $(100 \mu \mathrm{M})$ for 24 h. (h) Image fluorescence intensity of living materials before (gray) and after (green) addition of cumic acid for $24 \mathrm{~h}$ in LB media. (i-l) Fluorescence images $\left(\lambda_{\mathrm{ex}}=520-545 \mathrm{~nm}, \lambda_{\mathrm{obs}}=577-613 \mathrm{~nm}\right)$ of living materials comprising T1 and engineered $B$. subtilis senses IPTG $(1 \mathrm{mM})$ and fluoresces. The hydrogels were immersed in the (i $\& \mathbf{j})$ presence and $(\mathbf{k} \& \mathbf{l})$ absence of IPTG for $24 \mathrm{~h}$. (m) Image fluorescence intensity of living materials before (gray) and after (green) addition of IPTG for $24 \mathrm{~h}$ in LB media. Scale bars $=1 \mathrm{~cm} . N=3$ (biological replicates). Error bars represent \pm s.e.m. 

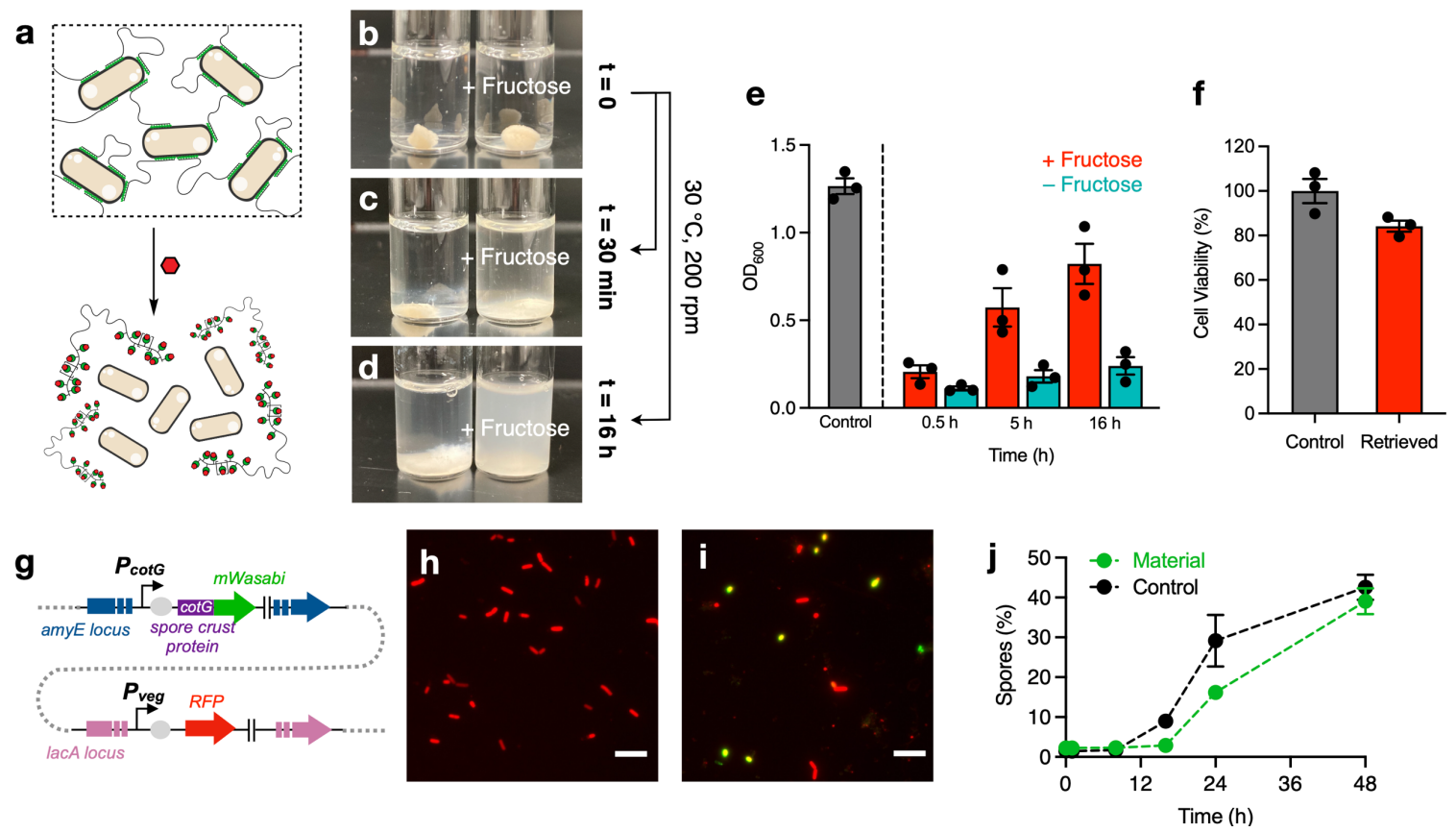

Figure 7. B. subtilis cells encased in polymeric living material can be retrieved and analyzed upon exposure to competitive diol species. (a) Schematic illustration of cell retrieval from living materials upon addition of competitive diol species. (b-d) Optical images of hydrogels immersed in PBS (20 mM, $\mathrm{pH} 7.4)$ in the absence (left) and presence (right) of fructose $(100 \mathrm{mM})$. These immersed hydrogels were mechanically agitated $(200 \mathrm{rpm})$ for 16 hours at $30^{\circ} \mathrm{C}$. (e) The absorbance at $600 \mathrm{~nm}\left(\mathrm{OD}_{600}\right)$ of supernatant from living materials immersed in PBS with fructose (red bar) and without fructose (green bar). The control (gray bar) contains the same number of cells, based on $\mathrm{OD}_{600}$, and is directly collected from the saturated bacterial cell culture. (f) Metabolic activities of retrieved cells (red bar) assessed by using 5-cyano-2,3-ditolyl tetrazolium chloride (CTC) reagent. The control contains the same number of cells, based on $\mathrm{OD}_{600}$, and is directly collected from the saturated bacterial cell culture. (g) Schematic illustration of the engineered genetic circuit of $B$. subtilis expressing intracellular RFP and displaying fluorescent fusion protein (CotG-mWasabi) on a mature spore surface. Representative fluorescence microscope images $\left(\lambda_{\mathrm{ex}}=530 \mathrm{~nm}, \lambda_{\mathrm{obs}}=605-670 \mathrm{~nm}\right.$ for RFP and $\lambda_{\mathrm{ex}}=488, \lambda_{\mathrm{obs}}=525-575 \mathrm{~nm}$ for mWasabi) of supernatant from living materials immersed in sporulation media for (h) $0 \mathrm{~h}$ and (i) $48 \mathrm{~h}$. (j) Sporulation percentages of $B$. subtilis in living materials immersed in sporulation media over $48 \mathrm{~h}$ (green). The control samples (black) contain the same number of cells in living materials and were immersed directly in sporulation media over 48 h. $N=3$ (biological replicates). Error bars represent \pm s.e.m. 


\section{ACKNOWLEDGMENT}

This work is supported by start-up funds from the University of California, Irvine. The authors also acknowledge the seed-funding support from the NSF Materials Research Science and Engineering Center (MRSEC), Center for Complex and Active Materials (CCAM) at the University of California, Irvine. The authors thank the Guan lab for use of their GPC, as well as Professor Guan for his helpful comments. Rheological measurements were performed at the Irvine Materials Research Institute Facility at the University of California, Irvine. Dynamic light scattering measurements were performed at the Laser Spectroscopy Labs, and the Nuclear Magnetic Resonance measurements were done in the NMR facility, both in the Department of Chemistry, University of California, Irvine.

\section{AUTHOR INFORMATION}

Department of Chemistry, University of California, Irvine, California 92697, United States.

Seunghyun Sim and Hyuna Jo

\section{Author Contributions}

S. S. conceived the project. S.S. and H. J. designed experiments. H. J. performed experiments. S. S. and H. J. analyzed the data and wrote the manuscript.

\section{Corresponding authors}

Correspondence to Seunghyun Sim (s.sim@uci.edu)

\section{Competing Financial Interests Statement}

The authors declare no competing financial interests. 


\section{REFERENCE}

1. Marks Jr, S. C.; Popoff, S. N., Bone cell biology: the regulation of development, structure, and function in the skeleton. American Journal of Anatomy 1988, 183 (1), 1-44.

2. Errington, J., Regulation of endospore formation in Bacillus subtilis. Nature Reviews Microbiology 2003, 1 (2), 117-126.

3. González, L. M.; Mukhitov, N.; Voigt, C. A., Resilient living materials built by printing bacterial spores. Nature chemical biology 2020, 16 (2), 126-133.

4. Huang, J.; Liu, S.; Zhang, C.; Wang, X.; Pu, J.; Ba, F.; Xue, S.; Ye, H.; Zhao, T.; Li, K., Programmable and printable Bacillus subtilis biofilms as engineered living materials. Nature chemical biology 2019, 15 (1), 34-41.

5. Kang, S.-Y.; Pokhrel, A.; Bratsch, S.; Benson, J. J.; Seo, S.-O.; Quin, M. B.; Aksan, A.; Schmidt-Dannert, C., Engineering Bacillus subtilis for the formation of a durable living biocomposite material. Nature communications 2021, 12 (1), 1-17.

6. Chakma, P.; Konkolewicz, D., Dynamic covalent bonds in polymeric materials. Angewandte Chemie 2019, 131 (29), 9784-9797.

7. Winne, J. M.; Leibler, L.; Du Prez, F. E., Dynamic covalent chemistry in polymer networks: A mechanistic perspective. Polymer Chemistry 2019, 10 (45), 6091-6108.

8. Marco-Dufort, B.; Iten, R.; Tibbitt, M. W., Linking molecular behavior to macroscopic properties in ideal dynamic covalent networks. Journal of the American Chemical Society 2020, 142 (36), 15371-15385.

9. Brooks, W. L.; Sumerlin, B. S., Synthesis and applications of boronic acid-containing polymers: from materials to medicine. Chemical reviews 2016, 116 (3), 1375-1397.

10. Deng, C. C.; Brooks, W. L.; Abboud, K. A.; Sumerlin, B. S., Boronic acid-based hydrogels undergo self-healing at neutral and acidic pH. ACS Macro Letters 2015, 4 (2), 220-224.

11. Smithmyer, M. E.; Deng, C. C.; Cassel, S. E.; LeValley, P. J.; Sumerlin, B. S.; Kloxin, A. M., Self-healing boronic acid-based hydrogels for 3D co-cultures. ACS macro letters $\mathbf{2 0 1 8}$, 7 (9), 1105-1110.

12. Yesilyurt, V.; Webber, M. J.; Appel, E. A.; Godwin, C.; Langer, R.; Anderson, D. G., Injectable self-healing glucose-responsive hydrogels with $\mathrm{pH}$-regulated mechanical properties. Advanced materials 2016, 28 (1), 86-91.

13. Cromwell, O. R.; Chung, J.; Guan, Z., Malleable and self-healing covalent polymer networks through tunable dynamic boronic ester bonds. Journal of the American Chemical Society 2015, 137 (20), 6492-6495.

14. Pasquina-Lemonche, L.; Burns, J.; Turner, R.; Kumar, S.; Tank, R.; Mullin, N.; Wilson, J.; Chakrabarti, B.; Bullough, P.; Foster, S., The architecture of the Gram-positive bacterial cell wall. Nature 2020, 582 (7811), 294-297.

15. Neuhaus, F. C.; Baddiley, J., A continuum of anionic charge: structures and functions of D-alanyl-teichoic acids in gram-positive bacteria. Microbiology and molecular biology reviews 2003, 67 (4), 686-723.

16. Allison, S. E.; D'Elia, M. A.; Arar, S.; Monteiro, M. A.; Brown, E. D., Studies of the genetics, function, and kinetic mechanism of TagE, the wall teichoic acid glycosyltransferase in Bacillus subtilis 168. Journal of Biological Chemistry 2011, 286 (27), 23708-23716. 
17. Chang, C.-W.; Bays, E.; Tao, L.; Alconcel, S. N.; Maynard, H. D., Differences in cytotoxicity of poly (PEGA) s synthesized by reversible addition-fragmentation chain transfer polymerization. Chemical communications 2009, (24), 3580-3582.

18. Alexeev, V. L.; Sharma, A. C.; Goponenko, A. V.; Das, S.; Lednev, I. K.; Wilcox, C. S.; Finegold, D. N.; Asher, S. A., High ionic strength glucose-sensing photonic crystal. Analytical chemistry 2003, 75 (10), 2316-2323.

19. Cao, K.; Jiang, X.; Yan, S.; Zhang, L.; Wu, W., Phenylboronic acid modified silver nanoparticles for colorimetric dynamic analysis of glucose. Biosensors and Bioelectronics 2014, 52, 188-195.

20. Liu, Y.; Deng, C.; Tang, L.; Qin, A.; Hu, R.; Sun, J. Z.; Tang, B. Z., Specific detection of D-glucose by a tetraphenylethene-based fluorescent sensor. Journal of the American Chemical Society 2011, 133 (4), 660-663.

21. Pappin, B.; Kiefel, M. J.; Houston, T. A., Boron-carbohydrate interactions. Carbohydratescomprehensive studies on glycobiology and glycotechnology 2012.

22. Angyal, S. J., The composition of reducing sugars in solution. In Advances in carbohydrate chemistry and biochemistry, Elsevier: 1984; Vol. 42, pp 15-68.

23. Angyal, S. J., The composition of reducing sugars in solution: Current aspects. Advances in carbohydrate chemistry and biochemistry 1991, 49, 19-35.

24. Brooks, W. L.; Deng, C. C.; Sumerlin, B. S., Structure-reactivity relationships in boronic acid-diol complexation. ACS omega 2018, 3 (12), 17863-17870.

25. Skarlatos, P.; Dahl, M. K., The glucose kinase of Bacillus subtilis. Journal of Bacteriology 1998, 180 (12), 3222-3226.

26. Blencke, H.-M.; Homuth, G.; Ludwig, H.; Mäder, U.; Hecker, M.; Stülke, J., Transcriptional profiling of gene expression in response to glucose in Bacillus subtilis: regulation of the central metabolic pathways. Metabolic engineering 2003, 5 (2), 133-149.

27. Olsen, B. D.; Kornfield, J. A.; Tirrell, D. A., Yielding behavior in injectable hydrogels from telechelic proteins. Macromolecules 2010, 43 (21), 9094-9099.

28. Phan, T. T. P.; Nguyen, H. D.; Schumann, W., Novel plasmid-based expression vectors for intra-and extracellular production of recombinant proteins in Bacillus subtilis. Protein expression and purification 2006, 46 (2), 189-195.

29. Castillo-Hair, S. M.; Fujita, M.; Igoshin, O. A.; Tabor, J. J., An engineered B. subtilis inducible promoter system with over 10000 -fold dynamic range. ACS synthetic biology 2019, 8 (7), 1673-1678. 